Pensares em Revista, ISSN 2517-2215

\title{
DA FORMAÇÃO DO LEITOR AO FORMADOR DE LEITORES DO TEXTO LITERÁRIO
}

Maria Fátima Xavier da Anunciação DE ALMEIDA (Universidade Federal de Mato Grosso do Sul) mfatima.ead.ufms@gmail.com

\begin{abstract}
Resumo: Neste texto, apresentamos alguns pontos de reflexão relacionados à formação do leitor do texto literário, particularmente do leitor formador, o professor de português e de literatura, que ensina literatura e trabalha com o texto literário nas séries finais do ensino fundamental e do ensino médio na educação básica brasileira e sul-mato-grossense.Trata-se de parte de discussão que vem sendo realizada em uma pesquisa, nas áreas inter-relacionadas de literatura e de educação, tendo como perspectivas teóricas a estética da recepção, o foco humanizador da literatura e a educação problematizadora. Nesse sentido, consideramos que o leitor formador é o principal responsável pelo trabalho pedagógico e estético com o texto literário na escola básica; portanto, tem a incumbência de formar leitores. Ele precisou ser formado por outros formadores de leitores. Passou pela escola básica, também, além de ter frequentado e concluído um curso de Letras. Todavia, o processo da formação inicial dele pode ter sido insuficiente, necessitando que haja uma formação continuada na área da educação literária. Discutimos essas questões, principalmente, por meio do pensamento de Bordini e Aguiar (1988), Candido (1995, 1997), Casa Nova (2001), Cosson (2012, 2016), Eagleton (1997), Freire (1987, 2003, 2005, 2011, 2013), Geraldi (2004), Jauss(2002), Lajolo (1988, 1997, 2001), Mortatti (2014) e Zilberman (1988, 1990, 1991, 2008, 2012).
\end{abstract}

Palavras-chave: Formação do leitor. Texto literário. Formação do professor. Ensino de literatura.

\section{ON LITERATURE-BASED INSTRUCTION AND THE TRAINING OF LITERACY TEACHERS}

Abstract: In this paper we present some reflection related to the formation of readers of literary texts, particularly in relation to the initial and in-service training of teachers of Portuguese and literature who work with the literary text in the late elementary school and high school in Brazil and particularly in Mato Grosso do Sul. These issues are part of the discussion that is being held in research, in the interrelated areas of literature and education, having the aesthetic of reception, the humanizing focus of literature teaching and the progressive education as theoretical perspectives. In this sense, we believe that the teacher fulfills an important role in the process: that of being responsible for the pedagogical and aesthetic work with literary texts in basic school. Therefore, he/she has the responsibility of developing a positive attitude to 
reading. This teacher was educated by other teachers. He/she went to elementary school. Besides he/she attended college and majored in Arts. However, the initial teacher training process may have been inadequate, and requires a continuing education in the field of literary education. We discussed these issues mainly through the thoughts of Bordini and Aguiar (1988), Candido(1995, 1997), Casa Nova (2001), Cosson (2012), Eagleton (1997), Freire (1987, 2003, 2005, 2011, 2013), Geraldi (2004), Jauss (2002), Lajolo (1988, 1997, 2001), Mortatti (2014) and Zilberman (1988, 1990, 1991, 2008, 2012).

Keywords: Reader education. Literary text. Teacher training Literature education.

\section{Introdução}

Apresentamos, neste artigo, alguns pontos de reflexão relacionados à formação do leitor do texto literário, particularmente do leitor dos anos finais do ensino fundamental e do ensino médio, incluindo, a formação do professor de português e de literatura.

A formação do leitor e do formador de leitores do texto literário ocorre na vida e na escola, em uma dada sociedade. Acompanha, por isso, seus valores sóciohistóricos e ideológicos e as renovações tecnológicas, que trazem vários suportes de leitura, seja por meio do livro impresso, a partir do século XIX, seja do livro digital, na contemporaneidade.

Nesse contexto, os leitores da "palavramundo", aqueles inseridos na escola de educação básica no Brasil e em Mato Grosso do Sul poderão ser os futuros professores de língua materna e formadores de leitores. Contudo, se a eles não for propiciado o acesso ao processo de letramento literário, torna-se difícil atribuírem valor à leitura do texto literário, doravante, leitura literária, e a incentivar a novos leitores.

\section{A formação do leitor na escola e na vida}

Como se forma um leitor? Paulo Freire nos dá uma pista para respondermos a pergunta. Conforme afirma o autor, expondo a sua experiência de leitor e a importância desse ato na formação do leitor crítico, "A leitura do mundo precede a leitura da palavra, daí que a posterior leitura desta não possa prescindir da continuidade da leitura daquele." (FREIRE, 2005, p. 11) a partir de remotas 
experiências de sua infância, adolescência e mocidade. Assim, a formação do leitor (literário) é desde sempre processo em constante movimento (DIAS, 2014).

Desse modo, constituímo-nos leitores à medida que vivemos em interação com a palavra (texto verbal ou não verbal), que está no mundo e o que foi escrito, dito pelo outro. Quando lemos, há um diálogo entre leitor/autor/texto (GERALDI, [1982]2004) e a realidade social, histórica e ideológica.

Então, "[...] a leitura é um processo de interlocução entre leitor/autor mediado pelo texto. Encontro com o autor, ausente, que se dá pela sua palavra escrita". (GERALDI, [1982]2004, p.91) O leitor, nesse processo, segundo Geraldi (2004) não é passivo, pois produz significações ilimitadas, dialógicas em suas leituras possíveis de um texto.

$\mathrm{O}$ ato de ler significa diálogo com o texto, descoberta de sentidos não-ditos e alargamento dos horizontes do leitor para realidades ainda não visitadas. Por isso, quanto mais contato com a literatura e com o universo dos livros tanto maior a chance de formarmos leitores competentes (AGUIAR, s.d.).

É nesse processo que se move a formação do leitor. Dessa forma, a constituição do leitor passa pelas leituras que leu nos múltiplos discursos postos na sociedade em que vive. Ela pode ocorrer na escola ou fora dela. Geralmente, se relaciona à escola, todavia, sabemos que isso não é verdade. O leitor se forma na vida também, com os outros (a família, os amigos, os parentes, etc.). "Como fonte de prazer e de sabedoria, a leitura não esgota seu poder de sedução nos estreitos círculos da escola." (LAJOLO, 1994, p.7)

A escola, instituição eleita para divulgar a escrita (ZILBERMAN, 2008), torna-se responsável por ensinar a palavra escrita, mediada por um professor e metodologias pedagógicas. Isso se dá utilizando livros, textos em seus diversos gêneros, sejam literários ou não literários. A instituição escolar

[...] constitui o espaço por excelência de aprendizagem, valorização e consolidação da leitura, cooperando com o processo de legitimação da literatura e da escrita no mundo capitalista. Ela conta, por seu turno, com uma história especial, de que fazem parte as diferentes filosofias educacionais, as concepções relativas aos processos de ensino, o modo de organização do aparelho pedagógico. Relativamente à leitura enquanto procedimento de decodificação de textos escritos, pressupõem-se tomadas de posição pelo menos sobre os seguintes tópicos: - 0 método de alfabetização; - o tipo de livro escolhido, se didático, pára-didático ou outro; - a educação artística e o ensino da literatura (ZILBERMAN, s.d.).

Antes mesmo da escolarização, o leitor do texto literário inicia a sua formação leitora em casa, provavelmente, com seus familiares, particularmente com a mãe ou 
com o pai, ao ouvir histórias infantis, de fadas e bruxas ou outras histórias, que criança adora ouvir. Até as cantigas de ninar fazem parte dessa leitura.

A importância, pois, dos primeiros contatos com a palavra é fundamental para a formação da sensibilidade linguística, isto é, a capacidade de prestar atenção nos sons e nos sentidos, no ritmo e na melodia de cada frase que ouvimos ou, depois, lemos, vai, gradativamente, aproximando-nos do texto escrito em todos os suportes e da literatura, especialmente. (s.d.)

Viver rodeado de material escrito não garante o nascimento de um leitor, no entanto, o exemplo dos pais, avós, irmãos, amigos, professores e bibliotecários é decisivo para aproximar a pessoa dos livros. Mas, é sobretudo o entusiasmo, o comprometimento demonstrado por meio da leitura conjunta, do diálogo sobre os assuntos lidos, da troca de livros, dos relatos de experiências leitoras que mobilizam o novo leitor (AGUIAR, s.d.)

$\mathrm{Na}$ escola brasileira, o leitor (aluno) passa pela educação infantil, pela alfabetização, anos iniciais e finais do ensino fundamental, ensino médio e mais adiante, poderá cursar a educação superior. Em cada uma das fases mencionadas, no processo de escolarização, a leitura pode ser concebida e ensinada de modos diferentes, porque temos múltiplos perfis de leitores a serem formados em cada tempo sócio-histórico, com diferentes objetivos, o que dependerá de concepções de homem, sociedade, educação, leitura e de literatura.

Além disso, há leitores em diferentes classes sociais que podem não ter tido acesso, pelas condições socioeconômicas familiares, a livros de literatura, ou tendo essas condições, não terem modelos de leitores que apreciem o texto literário, ficando, então, a cargo da escola a tarefa de Ihes propiciar o acesso aos textos literários e aos modelos de apreciadores da leitura literária.

Outra questão relevante sobre o tema é a formação do leitor crítico, que pode ser interditada se não tiver condições de acesso à escolarização, à alfabetização e ao letramento literário. Como nos adverte Freire (2005[1993], p. 10) indignado:

É um absurdo que estejamos chegando ao fim do século, fim do milênio, ostentando os índices de analfabetismo, os índices dos que e das que, mal alfabetizadas, estão igualmente proibidas de ler e de escrever, o número alarmante de crianças interditadas de ter escolarização e que com isso tudo convivamos quase como se estivéssemos anestesiados.

$E$, em pleno século $X X I$, essa realidade permanece no Brasil, em geral, e em Mato Grosso do Sul, em particular. No país, a taxa de analfabetismo, segundo informações recolhidas pelo IBGE, estava "[...] no patamar dos 10,0\%, o que 
correspondia a um contingente de 14,2 milhões de pessoas" (BRASIL, 2009). Já Mato Grosso do Sul, no mesmo período, contava com 8,1\% de pessoas analfabetas com 15 anos ou mais (BRASIL, 2009). Em 2011, o município de Campo Grande, entre a população de 10 a 15 anos, 1,64\% e, da população de 15 a 80 anos, 5,85\%, de pessoas não sabiam ler e escrever. (CAMPO GRANDE, Indicadores Educacionais da REME, 2011, p.14). Esses índices mostram que há muitos leitores da "palavramundo", ainda, interditados, porque não tiveram acesso à leitura e à escrita, logo ao processo de letramento.

Ao pensar na formação do leitor (literário), levamos em conta, ainda, que o leitor formula hipóteses construtivas do significado do texto. Preenche lacunas, faz deduções, comprova suposições por meio de um conhecimento do mundo em geral e das convenções literárias. (EAGLETON, 1997) Considerando a perspectiva das Teorias da Estética da Recepção, esse leitor ao ler o texto literário, utiliza quadros de referências pautadas em horizontes de expectativas (texto e leitor estão mergulhados em horizontes históricos, muitas vezes distintos e defasados). Os horizontes de expectativas são todas as convenções estético-ideológicas que possibilitam a produção/recepção de um texto (BORDINI; AGUIAR, 1988). É o que mostraremos na próxima seção deste texto.

\section{O leitor diante do texto literário: produção/recepção de sentidos}

A produção/recepção de sentidos pelo leitor se dá na relação entre este e o texto literário, em qualquer nível de ensino, em qualquer idade, durante a vida. Então, a mediação ocorre por meio do texto. A interlocução se processa entre o leitor, o texto e o autor. Nesse processo do ato de compreensão e interpretação do lido, o leitor faz a recepção do texto ou da obra literária, em que esta é, segundo Bordini e Aguiar (1988, p.82) "[...] uma concretização pertinente à estrutura da obra [ou texto], tanto no momento da sua produção como no da sua leitura, que pode ser estudada esteticamente [...]"

A concretização da recepção acontece na "[...] interação do leitor com o texto, em que este atua como pauta e tudo o que não diz ou silencia cria vazios que forçam aquele a interferir criadoramente no texto, a dialogar com ele, de igual para igual, num ato de comunicação legítimo". (BORDINI, AGUIAR, 1988, p. 82) 
Ao praticar a leitura literária, o leitor produz sentidos tendo como referência, de acordo com Zilberman (1990), ordens de convenções do horizonte de expectativas, quais sejam: social; intelectual; ideológica; linguística e literária. Acrescidas a elas, também, conforme Bordini e Aguiar (1988), temos as de cunho afetivos.

Zilberman (1990, p. 103) caracteriza cada uma das ordens explicando-as:

- social -, pois o indivíduo ocupa uma posição na hierarquia da sociedade;

- intelectual, porque ele detém uma visão de mundo compatível, na maior parte das vezes, com seu lugar no espectro social, mas que atinge após completar o ciclo de sua educação formal;

- ideológica, corresponde aos valores circulantes no meio, de que se imbui e dos quais não consegue fugir;

- lingüística, pois emprega um certo padrão expressivo, mais ou menos coincidente com a norma gramatical privilegiada, o que ocorre tanto de sua educação, como no espaço social em que transita;

- literário - proveniente das leituras que fez, de suas preferências e da oferta artística que a tradição, a atualidade e os meios de comunicação, incluindo-se aí a própria escola, Ihe concedem.

As de ordem afetiva, segundo Bordini e Aguiar (1988), provocam adesões ou rejeições das demais ordens, o que mostra a complexidade e a importância da noção de horizonte de expectativas. O leitor lê o texto (literário) com o seu horizonte de expectativas. Isso pode ocorrer de modo conflitante, pois

[...] a fusão de horizontes de expectativas se dá obrigatoriamente, uma vez que as expectativas do autor se traduzem no texto e as do leitor são a ele transferidas. O texto se torna o campo em que os dois horizontes podem identificar-se ou estranhar-se. Daí poder-se tomar a relação entre expectativas do leitor e a obra como parâmetro para a avaliação estética da literatura. (BORDINI; AGUIAR, 1988, p. 83)

As ordens de convenções do horizonte de expectativas possibilitam ao leitor produzir/recepcionar sentidos em suas leituras do texto literário, nos diversos espaços em que faz este ato. A escola é um desses espaços, que, por meio da mediação pedagógica do professor de português e de literatura, no ensino fundamental II e no ensino médio, propicia o contato do aluno com essas leituras e pode fazer um trabalho didático-pedagógico, construir uma pedagogia da leitura com vistas ao "letramento literário".

\section{O leitor escolar e o letramento literário}

O leitor (escolar) do texto (literário) tem "o direito à literatura" e este direito faz parte do que hoje se entende, a nosso ver, por "letramento literário", termo trazido por Cosson (2012), tomando-o emprestado das definições de letramento de Magda 
Soares (1998) e ampliado pelo autor. Conforme Cosson (2012), devemos compreender o letramento literário como uma prática social e ainda, parte dele se dá na escola. Segundo Cosson (s.d.), letramento literário é o processo de apropriação da literatura enquanto linguagem. É um ato contínuo e que está em movimento, que não se fecha. Ele começa com as cantigas, de ninar, passa por toda a nossa vida.

O termo mostra um caminho ao domínio de competências que o leitor adquirirá ao ler o texto literário, considerando-o prática social e histórica, de modo significativo, voltado à vida. De forma mais ampla, o que propõe o autor é "[...] reformar, fortalecer e ampliar a educação literária que se oferece no ensino básico". (id., p.12)

Assim, o trabalho com a leitura literária na esteira do letramento literário possibilita ao professor de português - que trabalha no ensino de língua e de literatura - repensar as habilidades que o leitor precisa adquirir para se tornar um leitor maduro e crítico. Diante disso, cabe a pergunta: quais competências o leitor precisa adquirir para ler o texto literário?

A resposta à pergunta anterior não é simples de responder, vai depender da concepção de leitura, literatura e de educação de cada professor de língua materna, que terá de criar uma pedagogia de leitura própria, levando em consideração conhecimentos interdisciplinares (filosofia, teoria literária, psicolinguística, linguística, sociologia, antropologia) e teorias de leitura, além do que parametrizam os planos nacionais, estaduais e municipais voltados ao ensino de linguagem e literatura para a escola brasileira.

A sistematização e a configuração de "saberes necessários à prática educativa" do professor de língua e de literatura, ao trabalhar na perspectiva do letramento literário (COSSON, 2012), damos o nome de pedagogia de leitura. Nessa linha de raciocínio, pensamos que esse professor precisa pensar e construir a sua pedagogia de leitura, para que o seu trabalho pedagógico com o texto literário ou não literário possibilite formar leitores mais críticos.

Propomos pensar a configuração de uma pedagogia de leitura, voltada particularmente, à leitura da literatura na educação básica brasileira, por meio das teorias de leitura da estética da recepção (ISER, 2002; JAUSS, 2002; LIMA, 2002; ZILBERMAN, 1988, BORDINI; AGUIAR, 1988), tendo como princípio que a leitura é uma prática social (ZILBERMAN,1988; LAJOLO, 1988,1997; SOARES, 1988), e a 
literatura tem papel de humanização (CANDIDO, 1995), numa concepção de educação problematizadora, por meio do diálogo (FREIRE, 2003, 2011, 2013).

Diante do exposto, e para pensar numa pedagogia de leitura, dentro de uma perspectiva sociológica, visualizamos o valor humanizador e estético da leitura literária. Assim, lançamos mão do pensamento de Candido (1995) e de Jauss (2002) por meio dos pressupostos da estética da recepção. Humanização em Candido (1995) é

[...] o processo que confirma no homem aqueles traços que reputamos e essenciais, como 0 exercício da reflexão, a aquisição do saber, a boa disposição para com o próximo, o afinamento das emoções, a capacidade de penetrar nos problemas da vida, o senso da beleza, a percepção da complexidade do mundo e dos seres, o cultivo do humor. A literatura desenvolve em nós a quota de humanidade na medida em que nos torna mais compreensivos e abertos para a natureza, a sociedade, o semelhante (CANDIDO, 1995, p. 249).

A natureza estética supera a dicotomia que se estabelece ao ler um texto literário: o trabalho e o prazer, pois segundo Jauss (2002)

[...] por um lado, prazer e trabalho formam, de fato, uma velha oposição, atribuída desde a Antigüidade ao conceito de experiência estética. À medida que o prazer estético se libera da obrigação prática do trabalho e das necessidades naturais do cotidiano, funda uma função social que sempre caracterizou a experiência estética. Por outro lado, a experiência estética não era, desde o princípio, oposta ao conhecimento e à ação (JAUSS, 2002, p. 95).

Em Freire fomos buscar a concepção de educação problematizadora, uma vez que, nesta, há um destaque da humanidade dos sujeitos. Essa humanidade é a característica mesma do diálogo, da intercomunicação entre os homens com o mundo e com os outros. Educandos e educadores se tornam sujeitos do processo educativo, quando se pensa no ensino de leitura literária na escola.

Vários pesquisadores e professores, ao longo de muitos anos de estudo, ensino e de pesquisa, vêm construindo/construíram a sua pedagogia de leitura voltada ao texto literário, para citar alguns deles, temos (COSSON, 2012; BORDINI e AGUIAR, 1988; MORTATTI, 2014; LAJOLO, 1988; GERALDI, [1982]2004; ZILBERMAN, 1988, 2012).

No depoimento de Cosson (2012, p. 11), lemos que o livro "Letramento literário: teoria e prática é uma proposta de ensino da leitura literária na escola básica. Resultado de vários anos de leitura, pesquisas, práticas de sala de aula minhas e de colegas, de alunos e de alunos de alunos." 
A obra de Bordini e Aguiar (1988), Literatura: a formação do leitor, alternativas metodológicas indica, no próprio título, o que denominamos uma pedagogia de leitura das autoras. E as palavras das autoras, na introdução do livro, confirmam o que defendemos.

Este livro [...] é uma tentativa de recuperação de um longo percurso de pesquisa, não no sentido do relato de experiências, mas como sistematização de tudo o que se pensou e comprovou, num texto de caráter teórico-metodológico. A partir de reflexões sobre a função social da leitura e o papel da escola na formação do leitor (capítulo 1), levanta dados sobre as expectativas dos alunos quanto à relação literatura - escola e sugere critérios para a seleção de textos no $1^{\circ}$ e $2^{\circ}$ graus (capítulo 2). Com base nesses pressupostos, discute a questão metodológica de ensino de literatura, enfatizando a necessidade de uma metodização das práticas pedagógicas centradas na natureza do literário e na comunicação leitor-obra (capítulo 3).

Apresenta, a seguir, cinco métodos de ensino de literatura, com fundamentação teórica diferenciada, objetivos e parâmetros de avaliação específicos, etapas de sistematização das atividades em sala de aula e unidades de ensino exemplificativas para os três níveis curriculares do $1^{\circ}$ e $2^{\circ}$ graus (capítulos 4 a 8). (BORDINI e AGUIAR, 1988, p. 7)

Mortatti (2014), em artigo intitulado Na história do ensino de literatura no Brasil: problemas e possibilidades para o século XXI, apresenta, além de outras reflexões, as suas opções teórico-metodológicas voltadas ao ensino de literatura para a escola básica brasileira, o que caracteriza a construção de sua pedagogia de leitura para formar professores. No excerto a seguir, comprovam-se algumas dessas proposições:

Ao iniciar a elaboração deste artigo, vieram-me à mente questões sobre as relações entre literatura, educação e ensino, das quais venho me ocupando desde a década de 1980, no exercício de minhas atividades como professora e pesquisadora. [...] Aos questionamentos iniciais, porém, sobrepuseram-se tanto a necessidade de dialogar com as urgências deste momento histórico quanto a compreensão da pertinência e atualidade do assunto. Abordá-los neste texto, portanto, pode representar a possibilidade de não somente reafirmar reflexões e pontos de vista, mas também de compor - ao estilo de Pierre Menard -, por meio de nova configuração textual, uma síntese do que venho elaborando há três décadas. (MORTATTI, 2014, p.24, grifos nossos.)

Ainda, conforme a autora, tratando do Ensino da literatura e leitura de configurações textuais, no referido artigo,

E, com base no conhecimento sobre o assunto, então disponível ou em construção, busquei formular proposta de abordagem e método de análise que contemplasse a complexidade e a singularidade do texto de literatura infantil e juvenil. Naquele momento, defini, de maneira mais sistemática, a necessidade de a análise contemplar os aspectos "intratextuais", "extratextuais" e "intertextuais" (MAGNANI, 1989) [...]. (MORTATTI, 2014, p.35- 36)

Lajolo (1988), no livro Leitura em crise na escola: as alternativas do professor, traz propostas que vão compondo as suas reflexões teóricas para o trabalho com o 
texto literário na escola. Cabe salientar que, em várias outros textos escritos pela autora $(1994 ; 2001)$, há posicionamentos teóricos que indicam a construção de uma pedagogia de leitura do texto literário.

Na obra organizada por Geraldi ([1982]2004]), O texto na sala de aula é possível ler proposta de trabalho com a leitura do texto literário direcionada a alunos do ensino fundamental II. Zilberman (1988, 1990, 2012), em diferentes obras, vai construindo também o arcabouço teórico-metodológico para fundamentar o que denominamos pedagogia da leitura. Para citar alguns autores/professores que construíram e vem construindo as suas pedagogias de leitura, voltadas ao texto literário.

A criação e a construção de uma pedagogia de leitura, com foco no texto literário, são processuais e se ligam às experiências, vivências e ao compartilhamento de vivências - a exemplo a produção acadêmica dos autores citados anteriormente - com os seus pares (alunos, colegas de profissão etc), às reflexões das leituras que fizeram ao longo de suas vidas pessoal e profissional. Também, temos de levar em conta a trajetória deles no lugar de leitores e de formadores de leitores. Por isso, o desafio de se construir uma pedagogia da leitura direcionada às diversas realidades das escolas brasileiras e seus diferentes leitores (alunos).

O professor de língua e de literatura da educação básica brasileira e sul-matogrossense também precisa criar e construir a sua pedagogia de leitura. É necessário que se conscientize disso, para que, na sua prática docente, no trabalho com o texto literário, forme leitores mais críticos e competentes. Sabemos que essa construção é um processo; todavia, deve-se querer e poder iniciá-la tão logo tenha a consciência dessa necessidade, pois haverá a possibilidade de efetivar o processo de letramento literário para os alunos da escola básica.

Nesse sentido, pensar numa pedagogia de leitura poderá garantir o letramento literário, que é um direito social do leitor (escolar), da mesma forma que preconiza Candido (1995) com relação ao direito à literatura, pois a escola, por meio de professores de língua e de literatura, tem a função de propiciá-lo aos estudantes brasileiros. Isso é verdadeiro tendo em vista, também, as competências de leitura literária para o contínuo processo do letramento literário (COSSON, 2012) desses alunos (leitores). 
Dado o exposto e concluindo esta parte de nosso texto, o direito à literatura e ao letramento literário está sendo negado a muitos brasileiros, como apontamos anteriormente, ao trazer as taxas de analfabetismo no país e em Campo Grande MS. Os professores de língua portuguesa, formadores de leitores também passaram pela escola básica brasileira e não tiveram esse direito garantido. Pensamos que essa realidade interfere na formação inicial do professor de Português no país, e em Mato Grosso do Sul em particular, quando o futuro docente irá trabalhar com o ensino de leitura e de literatura para formar leitores na escola básica. Mostramos uma reflexão mais aprofundada a esse respeito no próximo item deste texto.

\section{O leitor formador e a formação do leitor literário na escola}

O leitor formador, professor de Português, é o principal responsável pelo trabalho pedagógico e estético com o texto literário na escola básica brasileira, portanto, tem a incumbência de formar leitores. Esse professor precisou ser formado por outros formadores de leitores. Ele passou pela escola básica, também, além de ter frequentado e concluído um curso de Letras. Todavia, o processo da formação inicial dele pode ter sido insuficiente.

Outros fatores que influenciam essa formação podem ser citados: os aspectos socioeconômicos, dentro do modo de produção capitalista de nossa sociedade; a divisão das pessoas em classes sociais; as prioridades governamentais em oferecer educação a algumas camadas da população, excluindo outras, aí entra a questão da democratização da escola pública; as questões histórico-culturais e ideológicas; os conflitos de valores do que é literatura; o processo de construção e de apropriação de conhecimentos científicos sobre leitura, educação e literatura por parte dos formadores e de cada sistema educacional; a desvalorização do trabalho docente; a falta ou a demora de tomada de posição do estado em implantar políticas de formação de professores que valorizem a formação permanente; o investimento financeiro insuficiente do estado das três esferas federativas na educação; os aspectos afetivos que interferem no gosto e no querer ler o texto literário, dentre outros.

Diante desses aspectos complexos, que interferem na formação de formadores de leitores, a escola não tem conseguido atingir o letramento literário de seus 
alunos. Estabelece-se um círculo vicioso, uma vez que os formadores passaram pela escola básica e são eles que se tornarão professores de português dos anos finais do ensino fundamental e do ensino médio. Ainda, a esse respeito, estudiosos, para citar alguns, como Lajolo (1988; 1994); Zilberman (1988); Geraldi (2004); Leite (1983; 2004); Rocco (1981); Silva (2002); Soares (2001); Osakabe (2004); Cosson (2012) da área do ensino de língua, literatura e da leitura, fazem a crítica de como a escola vem tratando o ensino de leitura e de literatura dentro de uma prática burocratizante, mecânica, falseada e distanciada da vida, do cotidiano do aluno (leitor). A análise dos autores é válida e preocupante, pois é nessa escola e com os professores de língua materna e de literatura que se formam os futuros formadores de leitores.

Por meio de pesquisa que estamos construindo, desde 2013, sobre a formação inicial do professor de português, vimos que os professores, colaboradores do estudo, são leitores (formadores), que têm dentre as suas atribuições a função de formar leitores do texto literário. Frequentaram a educação básica brasileira, são docentes recém-formado em curso de Letras, irão trabalhar com o ensino de língua e de literatura no ensino fundamental II e no ensino médio em Campo Grande - MS, e poderão atuar, profissionalmente, em diferentes regiões e localidades do país.

Eles foram escolarizados, em sua maioria, em escolas públicas municipais e estaduais, formaram-se no Curso de Letras de uma universidade pública de Mato Grosso do Sul. Aprenderam a ler o texto literário com seus familiares, amigos e com professores na escola, ou desaprenderam a lê-lo, pois alguns familiares e professores de língua e de literatura, nos ambientes propícios para a prática da leitura literária, não a valorizam. Desse modo, o livro não terá um lugar e o gosto pelo ato de ler não se estabelecerá. Outro detalhe fundamental: a leitura da literatura forma leitores e não apenas transmite um patrimônio literário nacional. (ZILBERMAN, 2008)

Casa Nova (2001), em pesquisa sobre a história de leituras de professores, confirma o que expusemos.

Marcadas ora pela presença do(a) professor(a), dos pais, ora pela biblioteca que tinham a oportunidade de frequentar, essas professoras revelam a transitividade de suas primeiras leituras [...]. Cada professor-leitor faz transitar sua leitura em seu contexto social. Não é somente o indivíduo, o sujeito que está ali, lendo, mas as associações ali engendradas pela letra do texto que são trazidas sob forma de outros códigos (os sociais, os simbólicos, afetivos). (CASA NOVA, 2001, p.106). 
O relatório final de Retratos da leitura no Brasil corrobora com a defesa antecedente e aponta que "[...] muitos entrevistados afirmam que não leem ou não vão a bibliotecas porque 'não estão estudando', o que mostra a ligação da leitura com a escola, ou com 'os estudos', na percepção das pessoas." (CUNHA, 2008, p. 14, [Retratos da leitura no Brasil]) E mais, que

[...] $86 \%$ dos não-leitores nunca foram presenteados com livros na infância, enquanto no universo dos considerados leitores esse índice cai para 48\%. Outra informação importante diz respeito às práticas familiares de leitura. Nos lares dos não-leitores, $55 \%$ nunca viram os pais lendo. Se considerarmos que a maior influência para a formação da leitura vem dos pais (principalmente das mães). No entanto, dado o quadro de que os pais dos entrevistados não têm instrução alguma (23\%), cursaram até a $4^{a}$ série do ensino fundamental $(23 \%)$ ou têm fundamental incompleto (15\%), enquanto as mães sem qualquer escolaridade são $26 \%, 22 \%$ fizeram até a $4^{a}$ série e $16 \%$ têm fundamental incompleto, torna-se muito difícil a inculcação pela família do valor da leitura.

A leitura literária se estabelece relacionada à escolarização ou a não escolarização, todavia se a escola não tiver as condições de infraestrutura material e humana (biblioteca com acervos de livros de literatura, política de leitura, profissionais capacitados para atender a seus alunos leitores) e não valorizar a leitura, dificilmente haverá a promoção do gosto pela leitura literária.

Em Campo Grande - MS, por exemplo, em escola da rede estadual para o ensino básico, visitada pela autora, é recente a revitalização da biblioteca. Antes, a biblioteca servia de depósito de materiais alheios àquele espaço. Se não há a valorização da biblioteca, onde os alunos, que em sua maioria é da classe popular, desenvolverão o gosto pela leitura? Em casa com família? Parece difícil, pois os dados apresentados acima mostram que as famílias têm baixa escolaridade e podem, por isso, ter outros valores que não os da leitura do texto literário. Outros motivos que podemos apontar são: o não acesso ao livro literário, o baixo poder aquisitivo dos familiares para a compra desse material e a pouca oferta de bibliotecas públicas equipadas.

O professor de língua materna e de literatura como dissemos, anteriormente, passou pela escola básica brasileira, e, em sua maioria, não aprendeu a gostar de ler a literatura, somente na universidade pode ter sido despertado para esse gosto. É esse professor que é o formador de leitores da leitura do texto literário. Ele é antes de tudo é leitor-formador. Desse modo,

[...] a pessoa do professor constitui o principal fator para a promoção da leitura e, consequentemente, para a formação de leitores dentro da organização escolar: sem 
professores que sejam leitores maduros e assíduos, sem professores que demostrem uma convivência sadia com livros outros tipos de materiais escritos, sem professores capazes de dar aos alunos testemunhos vivos de leitura, fica muito difícil, senão impossível, planejar, organizar e instalar programas que venham a transformar, para melhor, os atuais procedimentos voltados ao ensino da leitura. (SILVA, 2002, p.69-70)

E nesse raciocínio, conforme Lajolo (1988, p. 53),

[...] se a relação do professor com o texto não tiver um significado, se ele não for um bom leitor, são grandes as chances de que ele seja um mau professor. E, à semelhança do que ocorre com ele, são igualmente grandes os riscos de que o texto não apresente significado nenhum para os alunos.

Não nos esqueçamos de que a formação do "mau professor" se produz também dentro de uma sociedade desigual, contraditória, em que, muitas vezes, é negado a ele o direito à leitura do texto literário, mesmo sendo esta legitimada por grupos dominantes. Desse modo, podemos, com Oliveira (2008), confirmar a proposição, pois a pesquisadora, ao estudar as relações entre formação, hábitos de leitura e práticas de ensino de literatura de professores de português do ensino médio da rede estadual da cidade de São Paulo apresenta o perfil desses docentes:

[...] originária de famílias com baixos níveis de escolarização, tendo tido pouco contato com a leitura durante a infância e constituindo a primeira geração a conquistar uma escolarização de longa duração. Essa escolarização, no entanto, se mostra precária quando analisados os dados que apontam para a frequência ao ensino básico público e ao ensino superior em instituições particulares, geralmente no período noturno. Tal formação não costuma levar esses professores a desenvolverem as disposições necessárias ao hábito da leitura literária, no sentido de se apropriarem das obras de literatura, reconhecendo-as efetivamente; apenas os leva a reconhecer o que é "legítimo" dentro da cultura letrada instituída. Dessa maneira, esses docentes tendem a reproduzir o conhecimento a que tiveram acesso, sem que tenham se tornado sujeitos de suas leituras e de tal conhecimento. (OLIVEIRA, 2008, p.177)

A escola e as instituições formadoras de leitores, incluindo os professores de português que formam leitores, considerando que são profissionais da área de língua e de literatura, atuantes nos anos finais do ensino fundamental e médio, não têm conseguido atingir esses leitores em sua maioria, pois o modo de produção capitalista atual não possibilita o acesso integral deles ao letramento literário, pela sua condição social e pelo direito negado a eles à leitura literária. Nesse sentido, surgem discursos da área acadêmica que insistem em culpabilizar, muitas vezes, os docentes que ensinam literatura, acusando-os de realizar uma prática pedagógica ineficiente nesta área; contudo, a história de leitura e a realidade socioeconômica e 
cultural podem não ter possibilitado a eles competências leitoras, que, por sua vez, interferem em seu fazer docente.

\section{Considerações finais}

Refletimos, neste texto, acerca da formação do leitor do texto literário, incluindo a do próprio leitor formador, que é professor de português e de literatura, principalmente, dos anos finais do ensino fundamental e do ensino médio na educação básica. O leitor formador frequentou a escola básica e um curso de Letras, contudo, isso pode não ter garantido a ele passar pelo processo do letramento literário, o que dificulta o desenvolvimento de competências leitoras, repercutindo em sua prática pedagógica ao trabalhar com a leitura do texto literário na escola. Uma formação precária no processo de letramento literário do leitor formador compromete a sua prática docente, perpetuando um círculo vicioso de fracasso do ensino de literatura, de modo mais abrangente, da prática com vista ao letramento literário.

Para romper com esse círculo, a escola e o leitor formador necessitam pensar em uma pedagogia da leitura do texto literário, norteada pelos fundamentos do letramento literário, investindo nas habilidades leitoras do leitor (aluno), que no futuro poderá ser o leitor formador.

\section{Referências}

AGUIAR, Vera Teixeira de. A formação do leitor. [s.d.] Disponível em: $<$ http://www.acervodigital.unesp.br/bitstream/123456789/40359/1/01d17t08.pdf>Ace sso em 08 set. 2014.

AMORIM, Galeno (Coord.); IBOPE inteligência; Observatório do livro e da leitura e Instituto Pró-livro [diretoria 2007/2008], São Paulo, 2a edição. Retratos da Leitura no Brasil, 2008. Disponível em: <http://p.download.uol.com.br/jc/

HTML_PORTAL/educacao/pesquisa_retratos_leitura_brasil.pdf >. Acesso 16 out. 2013.

BORDINI, Maria da Glória; AGUIAR, Vera Teixeira de. Literatura a formação do leitor: alternativas metodológicas. São Paulo: Mercado Aberto, 1988.

BRASIL. Instituto Brasileiro de Geografia e Estatística. Síntese de indicadores sociais: uma análise das condições de vida da população brasileira. Estudos e Pesquisas. Informação Demográfica e Socioeconômica, no 26 . Rio de Janeiro, 2009. Disponível em: <http://www.ibge.gov.br/home/estatistica/ 
populacao/condicaodevida/indicadoresminimos/sinteseindicsociais2009/indic_sociais 2009.pdf.> Acesso em: 29 set. 2014.

CAMPO GRANDE (MS). Secretaria Municipal de Educação. Superintendência de Gestão Estratégica. Indicadores educacionais da REME. CRUZ, Soraya Regina de Hungria et al. (Org.) Campo Grande: SEMED, 2011. Disponível em: $<$ http://www.capital.ms.gov.br/egov/downloadFile.php?id=4488\&fileField= arquivo_dow\&table=downloads\&key=id_dow\&sigla_sec=semed.>Acesso 04 agosto 2015.

CANDIDO, Antonio. O direito à literatura.In: Vários escritos, 3. ed. São Paulo: Duas Cidades, 1995.

Formação da literatura brasileira: momentos decisivos. (1750-1836). 8. ed. vol.1. Belo Horizonte - Rio de Janeiro: Editora Itatiaia limitada, 1997.

CASA NOVA, Vera. Leitura e cidadania. In. EVANGELISTA, Aracy Alves Martins; BRANDÃO, Heliana Maria Brina; MACHADO, Maria Zélia Versiani (Orgs.). A escolarização da literatura literária: o jogo do livro infantil e juvenil. 2. ed. Belo Horizonte: Autêntica, 2001.

COSSON, Rildo. Letramento literário: teoria e prática. 2. ed., - 2a reimpressão. São Paulo: Contexto, 2012.

- Letramento Literário. Glossário Ceale. Termos de Alfabetização, leitura e escrita para alfabetizadores. Faculdade de Educação de Minas Gerais. [s/d] Disponívelem:<http://ceale.fae.ufmg.br/app/webroot/glossarioceale/verbetes/ letramento-literario>. Acesso 09 março 2016.

DIAS, Ana Clélia Penha. A leitura literária no contexto escolar. Palestra de abertura do $15^{\circ}$ Encontro Programa do Livro e da Leitura (PROLER). Campo Grande - MS, 2014.

EAGLETON, Terry. Teoria da literatura: uma introdução. Tradução de Waltensir Dutra. 3. ed. São Paulo: Martins Fontes, 1997.

FREIRE, Paulo.Pedagogia da autonomia: saberes necessários à prática educativa. 28. ed. - São Paulo: Paz e Terra, 2003.

A importância do ato de ler: em três artigos que se complementam. 46 ed. - São Paulo, Cortez: Autores Associados, 2005. (Coleção polêmicas de nosso tempo).

FREIRE, Paulo. Educação como prática da liberdade. 14. ed. ver. atual. - Rio de Janeiro: Paz e Terra, 2011.

2013.

Pedagogia do oprimido. 54. ed. ver. e atual. - Rio de Janeiro: Paz e Terra,

GERALDI, João Wanderley (Org.). O texto na sala de aula. 3. ed. 9a reimpressão. São Paulo: Ática, [1982]2004. 
ISER, Wolfgang. O jogo do texto. In: LIMA, L. C. (Coord., sel., notas). A literatura e o leitor: textos de estética da recepção. 2. ed. Rio de Janeiro: Paz e Terra, 2002.

JAUSS, Hans Robert. A estética da recepção: colocações gerais. In: LIMA, L. C. (Coord., sel., notas). A literatura e o leitor: textos de estética da recepção. 2. ed. Rio de Janeiro: Paz e Terra, 2002.

LAJOLO, Marisa. Texto não é pretexto. In: ZILBERMAN, Regina (Org.). Leitura em crise na escola: as alternativas do professor. 9. ed. - Porto Alegre: Mercado Aberto, 1988.

1994.

Do mundo da leitura para a leitura do mundo. 2.ed. São Paulo: Ática,

LAJOLO, Marisa. Do mundo da leitura para a leitura do mundo. 3.ed. São Paulo: Ática, 1997.

. Literatura: leitores \& leitura. São Paulo: Moderna, 2001.

LEITE, Lígia Chiappini M. Invasão da catedral: literatura e ensino em debate. Porto Alegre - RS: Mercado Aberto, 1983.

LEITE, Lígia Chiappini de Moraes. Gramática e literatura: desencontros e esperanças. In: GERALDI, João Wanderley (Org.). O texto na sala de aula. 3. ed. 9ạ reimpressão. São Paulo: Ática, 2004.

LIMA, L. C. (Coord., sel., notas). A literatura e o leitor: textos de estética da recepção. 2. ed. Rio de Janeiro: Paz e Terra, 2002.

MORTATTI, Maria do Rosário Longo. Na história do ensino da literatura no Brasil: problemas e possibilidades para o século XXI. Educar em Revista, Curitiba, Brasil, n. 52, p. 23-43, abr./jun. 2014. Editora UFPR. Disponível em: <http://www.scielo.br/pdf/er/n52/03.pdf>. Acesso em: 05 set. 2014.

OLIVEIRA, Gabriela Rodella de. O professor de português e a literatura: relações entre formação, hábitos de leitura e prática de ensino. Dissertação de mestrado. Faculdade de Educação da Universidade de São Paulo. Programa de Pósgraduação em Educação. São Paulo, $2008 . \quad$ Disponível em: <http://www.teses.usp.br/teses/disponiveis/48/48134/tde-07102008-101148/ptbr.php>. Acesso em: 30 out. 2014.

OSAKABE, Haquira. Ensino de gramática e ensino de literatura. In: GERALDI, João Wanderley (Org.). O texto na sala de aula. 3. ed. 9ª reimpressão. São Paulo: Ática, 2004.

ROCCO, Maria Thereza Fraga. Literatura/Ensino: Uma Problemática. São Paulo: Ática, 1981.

SILVA, Ezequiel Theodoro da. Criticidade e leitura: ensaios. 1a reimpressão. Campinas, SP: Mercado de Letras Associação de Leitura do Brasil - ALB; Mercado de Letras, 2002. 
SOARES, Magda Becker. Letramento: um tema em três gêneros. Belo Horizonte: Autêntica, 1998.

SOARES, Magda. A escolarização da literatura infantil e juvenil. In: EVANGELISTA, Aracy Alves Martins; BRANDÃ̃O, Heliana Maria Brina; MACHADO, Maria Zélia Versiani (Orgs.). A escolarização da literatura literária: o jogo do livro infantil e juvenil. 2. ed. - Belo Horizonte: Autêntica, 2001.

ZILBERMAN, Regina (Org.). Leitura em crise na escola: as alternativas do professor. 9. ed. - Porto Alegre: Mercado Aberto, 1988.

ZILBERMAN, Regina. Literatura Infantil: livro, leitura, leitor. In: ZILBERMAN, Regina (Org.). A produção cultural para a criança. 4 ed. Porto Alegre - RS: Mercado Aberto, 1990.

ZILBERMAN, Regina. Recepção e leitura no horizonte da literatura. Alea [online]. 2008, vol.10, n.1, p. 85-97. Disponível em: <http://dx.doi.org/10.1590/S1517106X2008000100006.> Acesso em: 20 set. 2014.

ZILBERMAN, Regina. A leitura e o ensino da literatura. Curitiba: InterSaberes, 2012. (Série Literatura em Foco).

ZILBERMAN, Regina. A leitura no Brasil: sua história e suas instituições. [s/d]. Disponívelem:<http://www.unicamp.br/iel/memoria/projetos/ensaios/ensaio32.html>. Acesso 20 set. 2014. 
Artigo recebido em: 12 de outubro de 2015

Artigo aprovado em: 15 de junho de 2016

Sobre a autora:

Maria Fátima Xavier da Anunciação de Almeida é graduada em Letras e Pedagogia pela Universidade Católica Dom Bosco. Doutora em Letras pela Universidade Presbiteriana Mackenzie. Mestre em Educação pela Universidade Federal de Mato Grosso do Sul (2004). 